\title{
Automobile Gear Form Grinding Force Experiment and Forecasting of New Microcrystalline Grinding Wheels
}

\author{
Xinli Tian ${ }^{1}$, Lijun Yang ${ }^{1}$, Qian Liu ${ }^{1}$, Long Wang ${ }^{1}$, Lei Lei ${ }^{1}$, Heng Gao ${ }^{2}$, Yang \\ Zhang $^{3}$
}

${ }^{1}$ Science and Technology on Remanufacturing Laboratory, Academy of Armored Force Engineering, Beijing 100072

\author{
${ }^{2}$ Nanjing Artillery Academy, Nanjing 210000, China \\ ${ }^{3}$ Military deputy office of PLA in 674 factory, Harbin, 150056 \\ return_li@163.com
}

Keywords: New microcrystalline grinding wheels; Grinding force; Form grinding gear; Regression

\begin{abstract}
To study the grinding force of new grinding wheel of microcrystalline grinding wheel. The model of unreformed chip thickness was established. Based on orthogonal test, the influence of grinding wheel velocity vs, axial feed speed vw and radial feed ap were researched and analyzed. Results show that the maximum unreformed chip thickness, formal grinding forces and tangential grinding forces are in direct proportion to vw, ap and inversely proportional to vs. Among grinding parameters, vs has the most significant effect on grinding force, the second is wand the third is ap .
\end{abstract}

\section{Introduction}

The new type of microcrystalline grinding wheel is a kind of self-developed grinding wheel designed to solve the problem that the micro-grinding wheel used in the precision grinding process in China is completely dependent on the foreign import problem. In the grinding process, the microcrystalline grinding wheel is only the surface of the abrasive grain gradually off the grain, while a new grinding edge, with the micro-crystal particles off, but also brought a lot of grinding heat, improve the grinding wheel resistance Burn ability, it has a sharp, high self-sharpening, long life, grinding the advantages of small heat.

Grinding force is an important factor in the formation of grinding teeth impact grinding wheel wear and durability, surface quality and grinding temperature, it is mainly derived from the grinding wheel and tooth surface interference caused by elastic deformation, plastic deformation, cutting process and abrasive grain and The friction between the binder and the workpiece ${ }^{[1]}$, it is one of the most basic parameters to evaluate the grinding process and grinding wheel performance. Therefore, it is very important to measure and calculate the grinding force in gear grinding process.

In this paper, the mechanism of grinding force change in the grinding teeth of new microcrystalline corundum grinding wheel is revealed by the unreformed chip thickness model, and the variation of grinding force is analyzed by orthogonal test.

\section{Unreformed Chip Thickness}

The unreformed chip thickness has a great influence on the grinding force process. According to the geometrical relationship and the grinding principle, we can see that the effective abrasive grains per unit time are:

$$
N=C_{e} \bullet 2 l \bullet v_{s}
$$

Ce is the number of effective abrasive grains per unit area of the forming wheel, and 1 is the arc length of the involute. The product of the number of chips produced per unit time and the volume of each undeformed chip is equal to the volume removal rate. Fig. 1 is the physical model of 
undeformed chip, the shape can be approximated as a triangular pyramid, cross-section of a triangle, according to the three pyramids The formula to obtain the volume of a single chip $V_{c}$ :

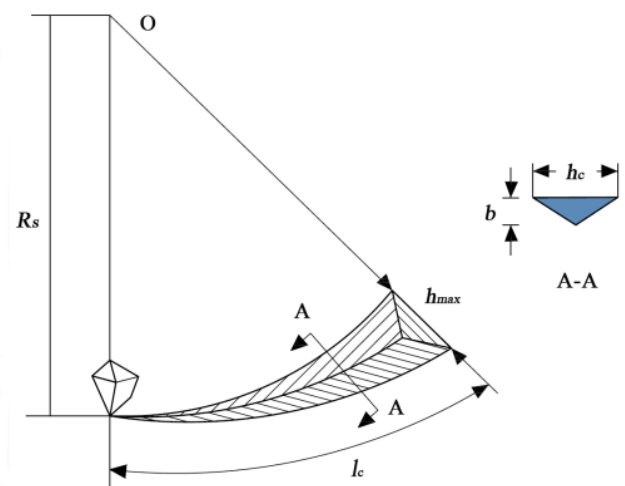

Figure 1. Undeformed chip model in grinding

$$
V_{c}=\frac{r h_{\mathrm{max}^{2}}^{2}}{2} \bullet \frac{l_{c}}{3}
$$

The removal volume $\mathrm{V}$ of the material per unit time is determined by the radial feed rate $a_{p}$ of the grinding wheel, the arc length $l$ of the gear involute, and the axial feed speed $v_{w}$ of the gear.which is $V=a_{p} v_{w} l$.the expression for the maximum undeformed thickness can be obtained:

$$
h_{\max }=\left[\frac{3}{C_{e} r}\left(\frac{v_{w}}{v_{s}}\right)\left(\frac{a_{p}}{l_{c}}\right)\right]^{1 / 2}
$$

As can be seen from the equation (3),hmax and vw, ap is proportional to the relationship, and vs is inversely proportional to, vs is about the wheel speed, therefore, by increasing vs to reduce hmax, so as to reduce the grinding force, improve the gear grinding surface Quality, reduce the purpose of grinding wheel wear.

\section{Experimental Scheme and Experimental Conditions}

Experimental Program. In this experiment, the grinding wheel speed vs, axial feed rate vw, radial feed ap, three factors, combined with the actual production of the factory and the machine itself performance parameters, as shown in Table 1, the factors taken 3 levels established grinding test And the average of the measured grinding forces was taken as the experimental result.

Table 1.The level-factor table of Orthogonal test

\begin{tabular}{cccc}
\hline factor & $v_{s} /\left(m \bullet s^{-1}\right)$ & $v_{w} /\left(m \bullet \mathrm{min}^{-1}\right)$ & $a_{p} /(\mu m)$ \\
\hline 1 & 30 & 1.5 & 50 \\
2 & 40 & 3.5 & 80 \\
3 & 50 & 5.5 & 100 \\
\hline
\end{tabular}

Experimental Device. The gear grinding experiment was carried out on the FANUC BV75 vertical machining center produced by Beijing Machine Tool Works. The spindle power was 15KW, the maximum speed was $7000 \mathrm{r} / \mathrm{min}$ and the maximum feed speed was $15 \mathrm{~m} / \mathrm{min}$. The grinding wheel is made of water-based coolant, and the workpiece is made of custom-made 20CrMnTi 
quenched steel gears. The grinding wheel is made of high-quality grinding wheel, and the grinding wheel is made of $200 \mathrm{~mm}$ diameter outer diameter, the mechanical properties shown in Table 1.

Table 2.Mechanical chacracteritics of 20CrMnTi

\begin{tabular}{cccccc}
\hline $\begin{array}{c}\text { Parameter } \\
\text { name }\end{array}$ & $\begin{array}{c}\text { Density } \\
\left(\mathrm{g} / \mathrm{cm}^{3}\right)\end{array}$ & $\begin{array}{c}\text { Elastic Modulus } \\
(\mathrm{GPa})\end{array}$ & $\begin{array}{c}\text { Poisson's } \\
\text { ratio }\end{array}$ & $\begin{array}{c}\text { Hardness } \\
(\mathrm{HRC}, \text { after } \\
\text { quenching })\end{array}$ & $\begin{array}{c}\text { Fracture } \\
\text { toughness }\end{array}$ \\
\hline Value & 7.835 & 206 & 0.25 & 62 & $\geq 69$ \\
\hline
\end{tabular}

Fig. 2 is set up in the machining center on the grinding wheel grinding system of microcrystalline grinding wheel, as shown in the figure of the microcrystalline grinding wheel in the high-speed rotation of the spindle, the use of flat clamp clamp fixture, and then installed in the dynamometer. The axial feed of the grinding process is achieved by the movement of the work table in the Y direction. Force device using the Swiss KISTLER 9275B high-performance strain gauge milling and drilling mill universal dynamometer to measure the grinding process grinding force.
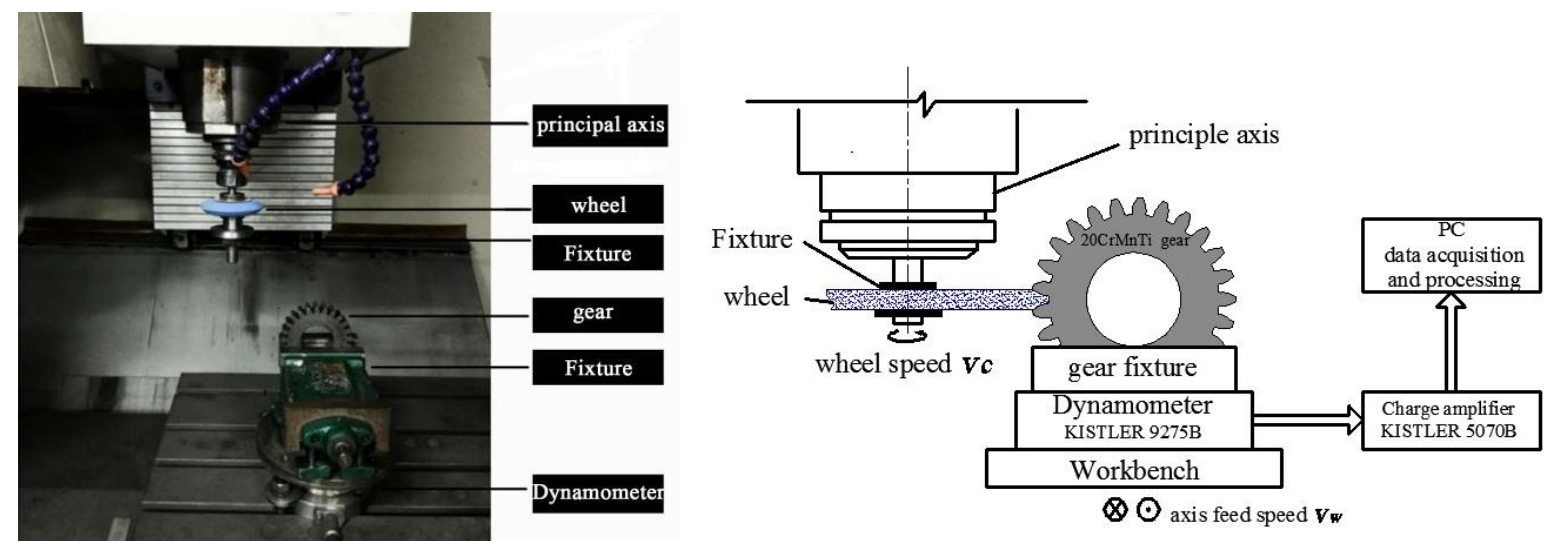

Figure 2. Form grinding gear experiment system based on machining center

\section{Experimental Results and Analysis}

In this paper, the orthogonal test of three factors and three levels of $L 9\left(3^{3}\right)=9$, each group of parameters under the test 3 times, a total of 27 tests were obtained grinding force results shown in Table 3 below. 
Table 3.Orthogonal test table and results of grinding forces

\begin{tabular}{cccccc}
\hline \multirow{2}{*}{$\begin{array}{c}\text { Experimen } \\
\text { t number }\end{array}$} & $\begin{array}{c}\text { Wheel } \\
\text { speed } \\
(\mathrm{m} / \mathrm{s})\end{array}$ & $\begin{array}{c}\text { axial feed } \\
\text { speed } \\
(\mathrm{m} / \mathrm{min})\end{array}$ & $\begin{array}{c}\text { radial feed } \\
(\mu \mathrm{m})\end{array}$ & \multicolumn{2}{c}{$\begin{array}{c}\text { Experimental } \\
\text { results }\end{array}$} \\
\cline { 5 - 6 } 1 & 30 & 1.5 & 50 & 26 & 42 \\
2 & 30 & 3.5 & 80 & 36.8 & 54 \\
3 & 30 & 5.5 & 100 & 46 & 68 \\
4 & 40 & 1.5 & 80 & 24.5 & 37.6 \\
5 & 40 & 3.5 & 100 & 34 & 53.8 \\
6 & 40 & 5.5 & 50 & 29.4 & 46 \\
7 & 50 & 1.5 & 100 & 24.3 & 37 \\
8 & 50 & 3.5 & 50 & 21.8 & 30 \\
9 & 50 & 5.5 & 80 & 28.3 & 42.4 \\
\hline
\end{tabular}

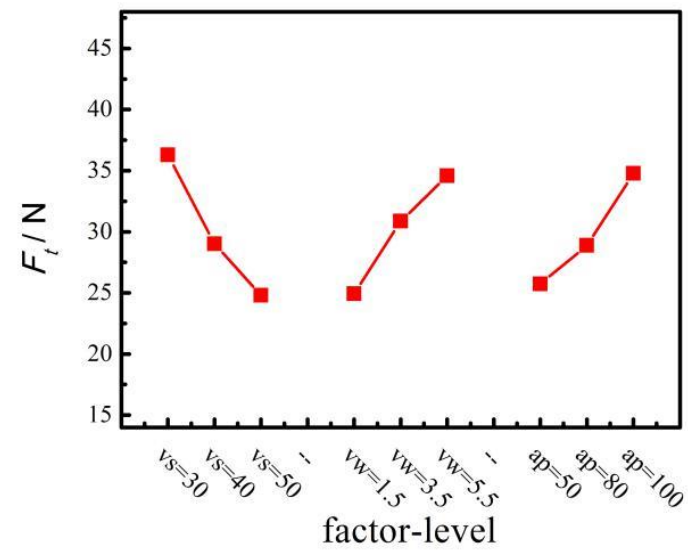

Figure 3. Trend of tangential grinding force

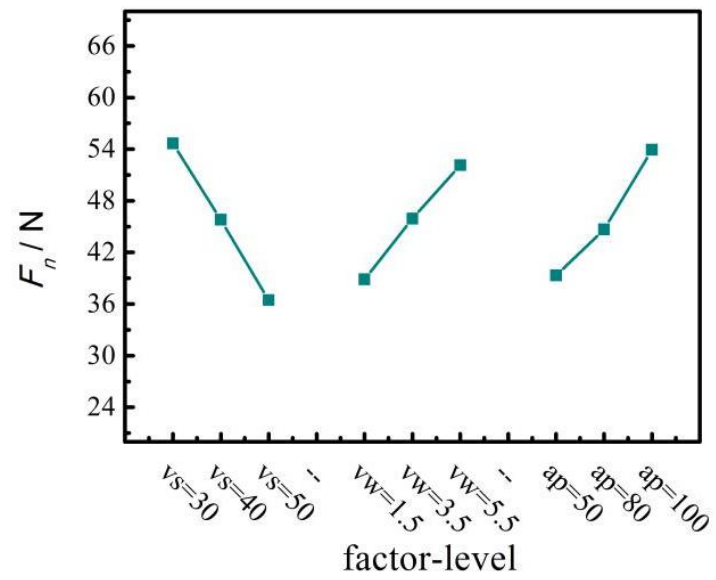

Figure 4. Trend of normal grinding force

Fig. 3 and Fig. 4 reflect the various factors in different levels of grinding force changes in the trend, we can see that the normal grinding force and tangential grinding force changes are similar, with the wheel speed increases, the two The value of both the normal grinding force and the tangential grinding force increase with the increase of the axial feed rate and the radial feed amount.

According to the equation 3, the maximum undeformed thickness $\left(h_{\max }\right)$ increases with the increase of $a_{p}$ and $v_{w}$, which leads to the increase of the grinding force. And with the increase of $v_{s}$, $h_{\max }$ increases and the grinding force fall down.

Analysis of the Extreme Difference of Grinding Force. Table 4 is the grinding force analysis of the extreme difference, you can see the wheel speed, axial feed rate and radial feed three factors on the tangential grinding force of the primary and secondary relations: wheel speed on the wheel The effect of grinding force is the largest, while the axial feed rate is the second and the radial feed is the least. The influence of process parameters on the normal grinding force can also be obtained. Primary and secondary sequence: The grinding wheel speed has the greatest influence on the grinding force, while the axial feed rate is the second. The radial feed has the least effect. 
Table 4. Grinding Force Analysis of Extreme Difference and Variance

\begin{tabular}{|c|c|c|c|c|c|c|c|}
\hline $\begin{array}{c}\text { Average } \\
\text { value }\end{array}$ & $v_{s}$ & $v_{w}$ & $a_{p}$ & $\begin{array}{c}\text { Average } \\
\text { value }\end{array}$ & $v_{s}$ & $v_{w}$ & $a_{p}$ \\
\hline$K_{l}$ & 36.28 & 24.93 & 25.73 & $K_{1}$ & 54.67 & 38.87 & 39.33 \\
\hline$K_{2}$ & 29.00 & 30.87 & 28.87 & $F n$ & 45.80 & 45.93 & 44.67 \\
\hline$K_{3}$ & 24.80 & 34.57 & 34.77 & $K_{3}$ & 36.47 & 52.13 & 53.93 \\
\hline $\begin{array}{c}\text { Extreme } \\
\text { difference R }\end{array}$ & 11.47 & 9.63 & 9.03 & $\begin{array}{c}\text { Extreme } \\
\text { difference R }\end{array}$ & 18.2 & 13.27 & 13.60 \\
\hline $\begin{array}{c}\text { Deviation } \\
\text { sum of } \\
\text { squares }\end{array}$ & 200.3 & 141.7 & 122.7 & $\begin{array}{c}\text { Deviation } \\
\text { sum of } \\
\text { squares }\end{array}$ & 496.9 & 264.4 & 281.7 \\
\hline$F$ radio & 1.293 & 0.915 & 0.792 & F radio & 1.429 & 0.760 & 0.810 \\
\hline
\end{tabular}

Analysis of Variance of Grinding Force. Table 4 also reflects the grinding process parameters on the normal grinding force and tangential grinding force of the significant level, we can see the grinding wheel speed, axial feed rate and radial feed rate on Fn, Ft effects are not significant.

\section{Conclusion}

The mathematical model of maximum undeformed cutting thickness $h_{\max }$ is established, and the influence of grinding wheel speed, axial feed speed and radial feedon grinding force is revealed based on $h_{\max }$. The grinding force orthogonal test is used to measure the grinding force The results show that the trend of tangential grinding force and normal grinding force decreases by $31.6 \%$ and $33.3 \%$ respectively when the linear velocity $v_{s}$ varies from $30 \mathrm{~m} / \mathrm{s}$ to $50 \mathrm{~m} / \mathrm{s}$, and the axial feed $v_{w}$ from $1.5 \mathrm{~m} / \mathrm{min}$ to $5.5 \mathrm{~m} / \mathrm{min}$, respectively, grinding force increase by $38.6 \%$ and $34.1 \%$ respectively. The radial feed ap, from $50 \mu \mathrm{m}$ to $100 \mu \mathrm{m}$, lead grinding force to increase by $35.1 \%$ and $34.6 \%$, respectively; The influence of grinding force on primary and secondary selation: $v_{s}>v_{w}>$ ap, and it was not significant that the three factors effects on $F_{t}$ and $F_{n}$.

\section{Reference}

[1] G. Werner:Annals of CIRP, Vol. 27(1978) No.1,p.243-248.

[2] S.Mlakin and N.H. Cook:Annals of the JEI,Vol.93(1971) p.1120-1133.

[3] J.Y. Tang,F. Yin and X.M. Chen:Annals of the MMT,Vol. 70 (2013) p.1-15.

[4] H.F. Chen,J.Y Tang and W. Zhou:Annals of the JMPT,Vol. 213(2013) p.717-721.

[5] B.M. Li and B. Zhao:Modern Grinding Technology(China Machine Press,Beijing 2003).

[6] Y. Wang,J.H. Xu and L. Yang:Annals of the OPE,Vol. 23(2015) No.7, p.2031-2042.

[7] Z.Y. Mi and Z.Q. Liang:Annals of the OPE,Annals of the ACTA ARMAMENTARII,Vol. 36(2015) No.6, p.1067-1073.

[8] X.Z. Ren and J.P. Ding:Annals of the KEM,Vol. 464(2011) p.401-404.

[9] B.F. Feng,G.D. Cai and X.L. Sun:Annals of theKEM,Vol. 304(2006) p.401-404.

[10] Y. Ohbuchi and T. Matsuo:Annals of the CIRP,Vol. 40(1991) No.1, p.401-404. 